\title{
Naphthalene-sulfonate inhibitors of human norovirus RNA-dependent RNA-polymerase
}

\author{
Delia Tarantino $^{\text {a }}$, Margherita Pezzullo ${ }^{\mathrm{a}, \mathrm{b}}$, Eloise Mastrangelo ${ }^{\mathrm{a}, \mathrm{b}}$, Romina Croci ${ }^{\mathrm{a}}$, Jacques Rohayem ${ }^{\mathrm{c}, \mathrm{d}}$, \\ Ivonne Robel ${ }^{\mathrm{d}}$, Martino Bolognesi ${ }^{\mathrm{a}}$, Mario Milani ${ }^{\mathrm{a}, \mathrm{b}, *}$ \\ a Department of Biosciences and CIMAINA, University of Milano, Via Celoria 26, I-20133 Milano, Italy \\ ${ }^{\mathrm{b}}$ CNR-IBF, Istituto di Biofisica, Via Celoria 26, I-20133 Milano, Italy \\ ' Institute of Virology, Dresden University of Technology, Fiedlerstrasse 42, 01307 Dresden, Germany \\ ${ }^{\mathrm{d}}$ Riboxx GmbH, Pharmapark Radebeul, Meissner Strasse 191, 01445 Radebeul, Germany
}

\section{A R T I C L E I N F O}

\section{Article history:}

Received 24 July 2013

Revised 31 October 2013

Accepted 28 November 2013

Available online 4 December 2013

\section{Keywords:}

Norovirus

Caliciviridae

RNA-dependent RNA polymerase

Antiviral discovery

X-ray crystallography

Naphthalene-sulfonate

\begin{abstract}
A B S T R A C T
Noroviruses are members of the Caliciviridae family of positive sense RNA viruses. In humans Noroviruses cause rapid onset diarrhea and vomiting. Currently Norovirus infection is responsible for 21 million gastroenteritis yearly cases in the USA. Nevertheless, despite the obvious public health and socio-economic relevance, no effective vaccines/antivirals are yet available to treat Norovirus infection.

Since the activity of RNA-dependent RNA polymerase (RdRp) plays a key role in genome replication and in the synthesis/amplification of subgenomic RNA, the enzyme is considered a promising target for antiviral drug development. In this context, following the identification of suramin and NF023 as Norovirus RdRp inhibitors, we analyzed the potential inhibitory role of naphthalene di-sulfonate (NAF2), a fragment derived from these two molecules. Although NAF2, tested in enzymatic polymerase inhibition assays, displayed low activity against $\mathrm{RdRp}\left(\mathrm{IC}_{50}=14 \mu \mathrm{M}\right)$, the crystal structure of human Norovirus RdRp revealed a thumb domain NAF2 binding site that differs from that characterized for NF023/suramin. To further map the new potential inhibitory site, we focused on the structurally related molecule pyridoxal-5'-phosphate-6-(2'-naphthylazo-6'-nitro-4', $8^{\prime}$-disulfonate) tetrasodium salt (PPNDS). PPNDS displayed belowmicromolar inhibitory activity versus human Norovirus $\operatorname{RdRp}\left(\mathrm{IC}_{50}=0.45 \mu \mathrm{M}\right)$, similarly to suramin and NF023. Inspection of the crystal structure of the RdRp/PPNDS complex showed that the inhibitor bound to the NAF2 thumb domain site, highlighting the relevance of such new binding site for exploiting Norovirus RdRp inhibitors.
\end{abstract}

(c) 2013 Elsevier B.V. All rights reserved.

\section{Introduction}

Noroviruses (NVs) are members of the Caliciviridae family of positive sense RNA viruses (Fauquet and Fargette, 2005; Green, 2007; Green et al., 2000; Mayo, 2002). Norovirus-linked gastroenteritis is estimated to affect $\sim 21$ million people annually in the United States, being responsible for up to 200,000 deaths per year in developing countries (Patel et al., 2008). The disease is usually acute and self-limiting, but in immunocompromised adults it can

Abbreviations: hNV, human Norovirus; mNV, murine Norovirus; RdRp, RNAdependent RNA-polymerase; PDB, protein data bank; NAF2, naphthalene-1,5disulfonic acid; PPNDS, pyridoxal-5'-phosphate-6-( $2^{\prime}$-naphthylazo-6'-nitro-4', $8^{\prime}$ disulfonate) tetrasodium salt.

* Corresponding author at: CNR-IBF, Department of Biosciences, University of Milano Via Celoria 26, 20133 Milano, Italy. Tel.: +39 02 50314898; fax: +39 02 50314895.

E-mail address: mario.milani@unimi.it (M. Milani). become chronic and persist for weeks-years (Bok and Green, 2012).

The NV genome $(7.7 \mathrm{~kb})$ contains three open reading frames (ORF1-3) of single stranded RNA. ORF1 is translated into a large polyprotein precursor, cleaved into six non-structural proteins (NS1-2, NS3, NS4, NS5, NS6 and NS7) by the viral protease (NS6); ORF2 and ORF3 encode for the capsid proteins VP1 and VP2, respectively (Clarke and Lambden, 2000). The structural and non-structural viral proteins that orchestrate the viral replicative machinery are potentially vulnerable targets for "attack" by proper ligands interfering with their functionality (Rohayem et al., 2010). The virus-specific nature of such targets, and their indispensable functions, provide the potential for limiting negative side effects of antiviral drugs on the physiologic host-cell processes.

In this context, we formerly identified suramin and the analogous compound NF023 as human and murine NV NS7 RNA-dependent RNA-polymerase (hNV- and mNV-RdRp, respectively) inhibitors (Mastrangelo et al., 2012). Our crystallographic analyses 
showed that the two inhibitors bind in an extended conformation to a common site, close to the enzyme catalytic center. Suramin and derivatives display poor membrane permeability (Beindl et al., 1996; Charlton et al., 1996; Klinger et al., 2001) due to the negative charges of their sulfonate groups, and would require chemical optimization to improve their drug-likeness. On the other hand, the suramin/NF023 binding site is located along the access pathway of incoming nucleoside triphosphates (NTPs) and is lined, in its central region, with lysine and arginine residues endowed with highly mobile side chains. Such conformational flexibility of the targeted binding site adds substantial complexity to the structure-based inhibitor optimization process. On such bases, we set out to investigate a fragment of the two mentioned inhibitors that, according to our crystal structures, mapped to the less flexible region (i.e. inner in the enzyme active site) of the suramin/NF023 binding site, likely representing their most inhibitory-active portion. We thus focused on naphthalene-1,5-disulphonic acid (NAF2; Fig. 1a) as a fragment of both suramin and NF023 'inhibitory heads', applying a sort of reverse fragment screening approach.

NAF2 was initially tested in enzymatic assays for inhibition of hNV-RdRp, showing modest activity $\left(\mathrm{IC}_{50}=14 \mu \mathrm{M}\right)$. Unexpectedly, however, the crystal structure of the hNV-RdRp/NAF2 complex showed that, besides the site previously characterized in the suramin/NF023 complexes, the compound bound also to a new thumb domain site, located in a cleft along the newly synthesized RNA exit path. Accordingly, the two NAF2 binding sites identified were named A-site ('old' site, common with suramin/NF023) and B-site ('new' site). In order to further characterize the B-site in view of its exploitation for inhibitor design, we then selected the NAF2 analog pyridoxal-5'-phosphate-6-(2'-naphthylazo-6'-nitro-4', 8' $^{\prime}$-disulfonate) tetrasodium salt (PPNDS, Fig. 1b), which our previous docking searches showed to potentially map to a region close to the B-site (Mastrangelo et al., 2012). PPNDS proved able to inhibit hNV-RdRp activity with an $\mathrm{IC}_{50}$ value in the sub-micromolar range $\left(\mathrm{IC}_{50}=0.45 \mu \mathrm{M}\right)$. Moreover, the crystal structure of the hNV-RdRp/ PPNDS complex showed that the inhibitor indeed bound to the Bsite previously mapped by NAF2. Our findings highlight a new RdRp inhibitory sub-site, and suggest that structure-based optimization of PPNDS may provide analogs with enhanced drug-likeness, shedding new light on the path towards anti-Norovirus drugs.

\section{Materials and methods}

\subsection{Chemicals}

For the RdRp inhibition assays poly $(\mathrm{C})$ and the NAF2 compound were purchased from Sigma-Aldrich, while PPNDS was from Santa Cruz Biotechnology. The compounds were dissolved at $100 \mathrm{mM}$ in $\mathrm{H}_{2} \mathrm{O}$ and stored at $-20^{\circ} \mathrm{C}$.

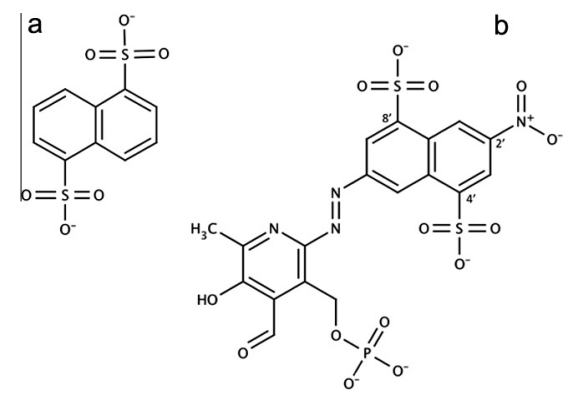

Fig. 1. Chemical structure of NAF2 (a) and PPNDS (b).

\subsection{Expression and purification of the $h N V-R d R p$}

hNV-RdRp was expressed in Escherichia coli and purified as previously described (Fullerton et al., 2007). The protein was dialyzed against buffer A (25 mM Tris/HCl, pH 7.4, 1 mM DTT, $100 \mathrm{mM} \mathrm{NaCl}$, $1 \mathrm{mM}$ EDTA) and concentrated to $9 \mathrm{mg} / \mathrm{ml}$. Protein concentration was determined with the BCA Protein assay kit (Pierce) based on the Biuret reaction.

\section{3. $h N V-R d R p$ inhibition assays}

In vitro RNA synthesis assays were performed as described (Mastrangelo et al., 2012). In brief the reaction mixture contained $20 \mathrm{mM}$ Tris/HCl (pH 7.5), $1 \mathrm{mM}$ DTT, $25 \mathrm{mM} \mathrm{NaCl}, 5 \mathrm{mM} \mathrm{MgCl}_{2}$, $0.3 \mathrm{mM} \mathrm{MnCl}$, $2 \mathrm{U}$ RiboLock Ribonuclease inhibitor, PicoGreen Quantitation Reagent, and as substrates poly $(\mathrm{C})$ template annealed with oligo(G) $)_{12}$ primer (62.5 nM final concentration), and $100 \mu \mathrm{M}$ GTP. Before starting the reaction, $1 \mu \mathrm{l}$ of the protein was incubated for $5 \mathrm{~min}$ in the presence of $1 \mu \mathrm{l}$ of water or $1 \mu \mathrm{l}$ of one inhibitor solution at the required concentration. The reaction was started by the addition of the reaction mixture to the incubated protein (final protein concentration $255 \mathrm{nM}$; inhibitor concentration from 0 to $20 \mu \mathrm{M}$ for NAF2, and from 0 to $10 \mu \mathrm{M}$ for PPNDS) up to a total volume of $200 \mu \mathrm{l}$. The reactions were followed for $10 \mathrm{~min}$ at $30{ }^{\circ} \mathrm{C}$ recording (every $30 \mathrm{~s}$ ) the fluorescence signals of the samples (in a Varian Cary Eclipse Fluorescence Spectrophotometer) arising from the interaction of the PicoGreen dye with the growing dsRNA. Protein activity was evaluated subtracting the slope of the linearly growing fluorescence from that of the same reaction mix win the absence of the enzyme. The results of three independent experiments were averaged. A plot of activity versus inhibitor concentration was used to estimate the $\mathrm{IC}_{50}$ values for each inhibitor (Table 1; Fig. S1) using the program GraFit (Erithacus software) or QtiPlot, using the four parameter equation:

$A=m+(M-m) \frac{1}{1+\left(\frac{[I]}{\left[C_{50}\right.}\right)^{n}}$

where $A=$ activity, $M=$ maximum activity, $m=$ minimum activity, $[I]=$ inhibitor concentration, $n=$ Hill coefficient (Prinz, 2010).

Independently, kinetic experiments were performed in order to determine the PPNDS hNV RdRp inhibition mechanism relative to the poly $(\mathrm{C}) / \operatorname{oligo}(\mathrm{G})_{12}$ substrate. Briefly, to explore the inhibition mode, we performed standard enzymatic reactions for which the $\operatorname{poly}(C) / \operatorname{oligo}(G)_{12}$ concentration was varied (from 3.9 to $125 \mathrm{nM}$ ), at $100 \mu \mathrm{M}$ GTP constant concentration, applying increasing amounts of the inhibitor (from 0 to $1 \mu \mathrm{M}$ ). The assays were performed using a TECAN Infinite 200 PRO microplate reader; the results were analyzed through Lineweaver-Burk plots ( $1 /$ V versus 1 / $[S])$ at varying PPNDS concentrations.

\subsection{Biophysical characterization of the hNV-RdRp/inhibitor interaction}

Thermofluorimetric (Thermal shift) assays for the evaluation of the hNV-RdRp melting temperature $\left(T_{\mathrm{m}}\right)$ in the absence/presence of the inhibitors were conducted in a MiniOpticon Real Time PCR Detection System (Bio-Rad), using the fluorescent dye Sypro Orange. $4 \mu \mathrm{l}$ aliquots of hNV-RdRp solution (final protein concentra-

Table 1

$\mathrm{IC}_{50}$ values of the different compounds against hNV-RdRp.

\begin{tabular}{ll}
\hline Cpd & hNV-RdRp IC $50(\mu \mathrm{M})$ \\
\hline Suramin & $0.24 \pm 0.08$ \\
NAF2 & $14.0 \pm 1.0$ \\
PPNDS & $0.45 \pm 0.09$ \\
\hline
\end{tabular}


tion $34.7 \mu \mathrm{M}$ ) were diluted in $18 \mu \mathrm{l}$ of its buffer, and mixed with $3.5 \mu \mathrm{l}$ of Sypro orange (Sigma) diluted $60 \times$, and PPNDS (5 or $50 \mu \mathrm{M}$ ), or $700 \mu \mathrm{M}$ NAF2. In control samples the inhibitor solutions were replaced by water. The sample plates were heated from 20 to $90{ }^{\circ} \mathrm{C}$, with a heating rate of $0.2^{\circ} \mathrm{C} / \mathrm{min}$. Fluorescence intensities were measured within excitation/emission ranges of $470-505 \mathrm{~nm}$ and $540-700 \mathrm{~nm}$, respectively.

\subsection{Crystallization of the $h N V-R d R p$ in presence of NAF2 and PPNDS}

Sitting drop crystallization experiments for hNV-RdRp (11 mg/ $\mathrm{ml}$ stock enzyme concentration) were assembled using an Oryx-8 crystallization robot (Douglas Instruments, East Garston, UK), from a $50 \%, 67 \%, 80 \%$ mixture of the protein with the reservoir solution (final drop volume $0.3 \mu \mathrm{l}$ ). Crystals grew in about 4 weeks, at $20^{\circ} \mathrm{C}$, in $1.2 \mathrm{M}$ Na citrate, $100 \mathrm{mM}$ Na cacodylate, $\mathrm{pH}$ 6.2, $\mathrm{NaCl} 125 \mathrm{mM}$. Before X-ray data collection, crystals were soaked in a cryoprotectant solution (1.4 M Na citrate, $100 \mathrm{mM}$ Na cacodylate $\mathrm{pH} 6.2$, and $25 \%$ glycerol) containing $30 \mathrm{mM}$ NAF2, for $24 \mathrm{~h}$, or containing $5 \mathrm{mM}$ of PPNDS, $62.5 \mathrm{nM}$ dsRNA (poly(C)/oligo(G) $)_{12}$ ) and $100 \mu \mathrm{M}$ GTP, for $36 \mathrm{~h}$. The soaked crystals were then flash-cooled in liquid nitrogen. The hNV-RdRp/NAF2 crystals diffracted to a maximum resolution of $2.04 \AA$ at the Elettra Synchrotron source (Trieste, Italy), beam line XRD1. The hNV-RdRp/PPNDS crystals diffracted to a maximum resolution of $2.6 \AA$ at the ESRF Synchrotron facility (Grenoble, France), beam line ID29.

hNV-RdRp/NAF2 X-ray diffraction data were indexed using MOSFLM (Read et al., 2007), and intensities were merged using SCALA (Evans, 2006). hNV-RdRp/PPNDS X-ray diffraction data were indexed and scaled using XDS (Kabsch, 2010). The hNV-RdRp crystals grown in the presence both of NAF2 or PPNDS display closely similar unit cells and belong to the orthorhombic space group I222; data collection statistics are reported in Table 2.

Table 2

$\mathrm{X}$-ray data-collection and refinement statistics for hNV-RdRp/NAF2 and for hNVRdRp/PPNDS

\begin{tabular}{lll}
\hline Protein & hNV-RdRp/NAF2 & hNV-RdRp/PPNDS \\
Soaked compound & NAF2, 30 mM & PPNDS, 5 mM \\
Ligand site(s) present & A-site, B-site & B-site \\
Beam line \& wavelength $(\AA)$ & ELETTRA XRD1 & ESRF ID29 1.072 \\
& 1.000 & \\
Space group & I222 & I222 \\
Unit-cell parameters $(\AA)$ & $\mathrm{a}=86.6 ; \mathrm{b}=111.8 ;$ & $\mathrm{a}=85.8 ; \mathrm{b}=116.1 ;$ \\
& $\mathrm{c}=121.4$ & $\mathrm{c}=122.1$ \\
Molecules in a.u. & 1 & 1 \\
Resolution $(\AA)$ & $45.4-2.04$ & $38.4-2.6$ \\
Mosaicity $\left({ }^{\circ}\right)$ & 0.6 & 0.4 \\
Measured reflections & $138,897(20,166)^{\mathrm{a}}$ & $87,361(6,478)^{\mathrm{c}}$ \\
Unique reflections & $37,405(5,330)$ & $19,046(1,383)$ \\
Completeness $(\%)$ & $98.7(97.7)$ & $99.6(99.7)$ \\
Redundancy & $3.7(3.8)$ & $4.6(4.7)$ \\
$\mathrm{R}_{\text {merge }}(\%)$ & $10.3(41.7)$ & $10.4(73.8)$ \\
Average $I / \sigma(I)$ & $9.1(2.7)$ & $12.1(1.9)$ \\
$\mathrm{R}_{\text {factor }} / \mathrm{R}$ free ${ }^{\mathrm{c}}(\%)$ & $17.0 / 22.3$ & $22.0 / 28.5$ \\
r.m.s. Bonds $(\AA)$ & 0.010 & 0.008 \\
r.m.s. Angles $\left({ }^{\circ}\right)$ & 1.37 & 1.18 \\
Average protein $B$ fac. $\left(\AA^{2}\right)$ & 22.4 & 57.5 \\
Average ligand $B$ fac. $\left(\AA^{2}\right)$ & $\mathrm{B}-\mathrm{site}=20.9$ & $\mathrm{~B}-\mathrm{site}=85.2$ \\
& $\mathrm{~A}-\mathrm{site}=32.2$ & \\
Residues in most favored & 93.4 & 91.8 \\
$\quad$ regions $(\%)$ & & \\
Residues in additionally & 6.6 & \\
$\quad$ allowed regions $(\%)$ & $4 \mathrm{LQ} 9$ & \\
PDB-ID & & \\
\hline
\end{tabular}

Values in parentheses are for the highest resolution shell: ${ }^{\mathrm{a}}(2.15-2.04){ }^{\mathrm{b}}(2.66-$ 2.60).

${ }^{a} R_{\text {merge }}=\Sigma|I-(I)| / \Sigma I \times 100$, where $I$ is intensity of a reflection and $(I)$ is its average intensity.

${ }^{\mathrm{b}} R_{\mathrm{factor}}=\Sigma\left|F_{\mathrm{o}}-F_{\mathrm{c}}\right| / \Sigma\left|F_{\mathrm{o}}\right| \times 100$.

c $R_{\text {free }}$ is calculated on $5 \%$ randomly selected reflections, for cross-validation.

\subsection{Structure determination and refinement}

The three-dimensional structures of hNV-RdRp in the complexes with NAF2 and PPNDS were solved by the Molecular Replacement method using the program MOLREP (Vagin and Teplyakov, 1997) and a search model based on the structure of the hNV-RdRp from strain Hu/NLV/Dresden174/1997/GE (PDB-id 2B43). The single molecule present in the crystal asymmetric unit was subjected to rigid-body refinement, and subsequently to constrained refined using REFMAC5 (Steiner et al., 2003). A random set comprising $5 \%$ of the data was omitted from refinement for R-free calculation. Manual rebuilding with COOT (Emsley et al., 2010); additional refinement with BUSTER (Smart et al., 2012) and REFMAC5, were subsequently performed, as needed. Refinement statistics as well as stereochemical quality assessment of the 3D structures are summarized in Table 2. Atomic coordinates and structure factors for hNV-RdRp in complex with NAF2 and PPNDS have been deposited with the PDB (Berman et al., 2000) with accession codes 4LQ9 and 4LQ3, respectively.

\section{Results}

\subsection{In vitro inhibition of $h N V-R d R p$}

In vitro RNA synthesis assays were performed using annealed $\operatorname{poly}(\mathrm{C})-\operatorname{oligo}(\mathrm{G})_{12} \quad(62.5 \mathrm{nM}$ final concentration) and GTP (100 $\mu \mathrm{M}$ final concentration), as polymerase substrates, and $255 \mathrm{nM}$ RdRp, following procedures previously described (Mastrangelo et al., 2012). Under these experimental conditions, NAF2 inhibited hNV-RdRp activity with $\mathrm{IC}_{50}=14 \mu \mathrm{M}$ whereas PPNDS inhibited the enzyme with an $\mathrm{IC}_{50}$ value of about $0.45 \mu \mathrm{M}$ (Table 1 ; Fig. S1). Furthermore, analyzing the dose-response curves for NAF2, it is evident that the number of bound inhibitor molecules is higher than 1 (Prinz, 2010). As described in the next paragraph, such value is in agreement with the crystal structure data, where we observed two ligand binding sites (see below).

We also analyzed the kinetic mechanism of hNV-RdRp inhibition by PPNDS (Fig. 2). The Lineweaver-Burk plots highlighted a non-competitive inhibition mechanism with respect to the $\operatorname{poly}(\mathrm{C}) / \operatorname{oligo}(\mathrm{G})_{12}$ substrate, with a $K i$ value of $0.52 \pm 0.05 \mu \mathrm{M}$, indicating that the inhibitor is able to bind to the free enzyme as well as to the enzyme-substrate complex.

In order to verify whether the selected compounds might induce some form of destabilization/denaturation of the enzyme, generally reflected by a variation of the protein $T_{\mathrm{m}}$, we performed thermofluorimetric assays. The acquired data showed that hNVRdRp displays the same $T_{\mathrm{m}}$ in the absence $\left(T_{\mathrm{m}}=36.9 \pm 0.5^{\circ} \mathrm{C}\right)$ or in the presence of NAF2 $\left(0.7 \mathrm{mM} ; T_{\mathrm{m}}=37.5 \pm 0.4^{\circ} \mathrm{C}\right)$. The thermofluorimetric signal recorded in the presence of PPNDS is markedly reduced when the inhibitor concentration is raised, since the red colored inhibitor molecule absorbs part of the incident radiation (in the 470-505 $\mathrm{nm}$ range). We were however able to test the effects on $T_{\mathrm{m}}$ at two PPNDS concentrations ( 5 and $50 \mu \mathrm{M}$ ), resulting in $T_{\mathrm{m}}$ values of $37.0 \pm 0.5$ and $41.0 \pm 2.0$, respectively (Fig. S2a and b). Despite the low fluorescence signal recorded in the presence of $50 \mu \mathrm{M}$ PPNDS, the slight Tm increase observed would imply some protein stabilization induced by the bound inhibitor. All the thermofluorimetric results prove that the hNV-RdRp inhibition is not due to inhibitor-linked adverse effects on enzyme stability/ denaturation.

\subsection{Crystal structures of $h N V-R d R p$ with NAF2}

\subsubsection{Inhibitor binding to the B-site}

The analysis of NAF2 binding to the RdRp domain was addressed through X-ray crystallography. To this purpose, 

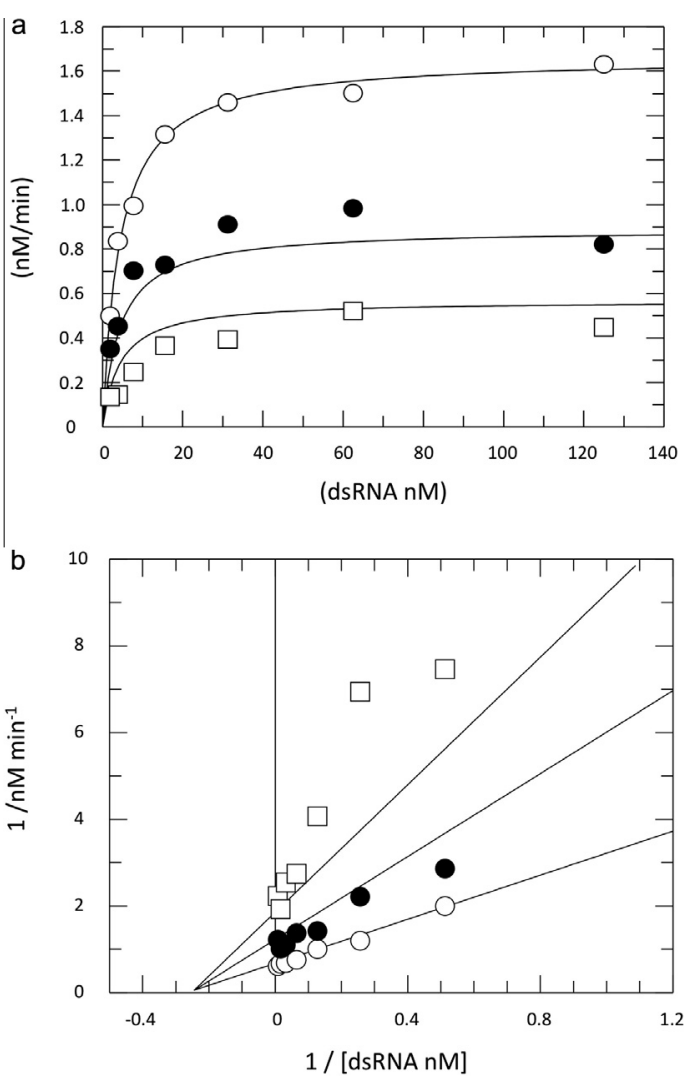

Fig. 2. (a) Reaction velocity plot as a function of the RNA concentration, $\bigcirc$ in absence of the inhibitor, $\bullet$ in presence of $0.45 \mu \mathrm{M}$ of PPNDS and $\square$ in presence of $1 \mu \mathrm{M}$ of PPNDS. (b) Lineweaver-Burk double reciprocal plot for the non competitive inhibition mechanism of hNV RdRp activity by PPNDS, relative to RNA substrate.

hNV-RdRp crystallization experiments were performed in presence of NAF2 (see Section 2for details). The hNV-RdRp crystals were soaked in $30 \mathrm{mM}$ NAF2 before cryo-cooling, The crystal (belonging to the orthorhombic space group 1222 , with one molecule per asymmetric unit) diffracted to a maximum resolution of $2.04 \AA$, and the structure was refined to a final crystallographic R-factor of $17.0 \%$ and $\mathrm{R}$-free of $22.3 \%$ (Table 2). The first refinement cycles showed residual electron density compatible with a NAF2 molecule located in a positively charged cleft within the thumb domain (Fig. 3a and b), built by an $\alpha$ - $\beta$-loop- $\alpha$ motif; inspection of the enzyme structure confirms that this site (hereafter, the B-site) is different from the binding site where suramin and NF023 inhibitors were located (hereafter, the A-site). In the B-site, the negative charges of NAF2 sulfonates are balanced by Arg419 and Arg436; the naphthalene ring is sandwiched between Gln414 and Gln439 (forming an intertwined hydrogen bond network together with Asn505), on one side, and Phe28 and Arg419, on the other (Fig. 3b). Additional polar interactions involve the side chains of Asn505 and Thr418 and the main chain nitrogen of Arg419. Inspection of the hNV-RdRp/NAF2 crystal structure in comparison to the enzyme 3D structure in the absence of inhibitors (pdb-id: 2B43, r.m.s.d. $0.70 \AA$, over 499 C $\alpha$ pairs) shows that, upon NAF2 binding, the protein undergoes only slight structural rearrangements at a few residues, and at the last two C-terminal residues, Asn505 and Glu506, visible in the electron density.

\subsubsection{Inhibitor binding to the A-site}

Further inspection of difference Fourier maps revealed residual electron density compatible with one NAF2 molecule in the A-site (Fig. 3a and c), i.e. at a location very close to the site occupied by the naphthalene-sulfonate moiety of NF023/suramin, in the fingers domain (Fig. 3c; Mastrangelo et al., 2012). Lys171, Lys174, Lys180 and Arg182 stabilize the inhibitor negative charges; the sulfonate groups establish H-bonds with Gln66 and the main chain $\mathrm{N}$ atom of Lys171. Additionally, the naphthalene ring makes $\pi$-cation interactions with Lys174 and Arg182 (Fig. 3c).

\subsection{Crystal structure of $h N V-R d R p$ bound to PPNDS}

In a previous virtual screening search targeting a wide region around the hNV-RdRp active site, we identified PPNDS, a compound hosting a naphthalene disulfonate moiety, among other potential NV-RdRp inhibitors (Mastrangelo et al. 2012). Analysis of the simulated structure showed that PPNDS would locate in a

a

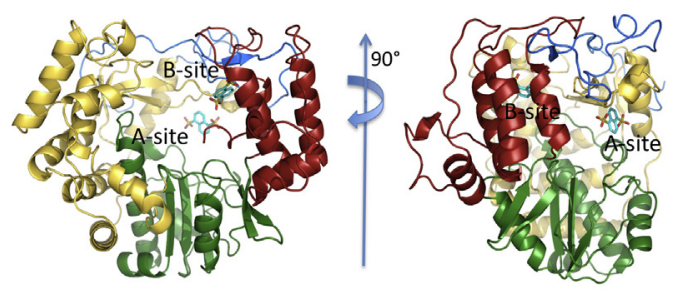

b

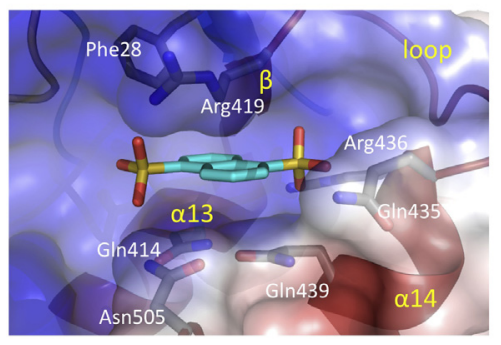

C

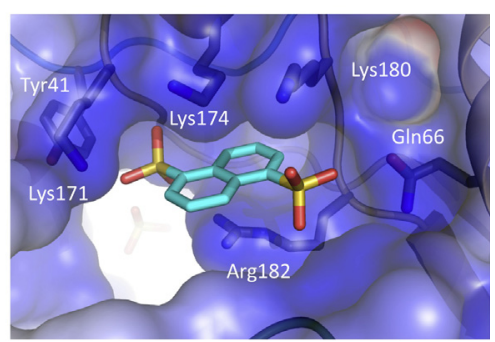

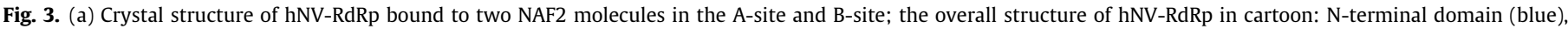

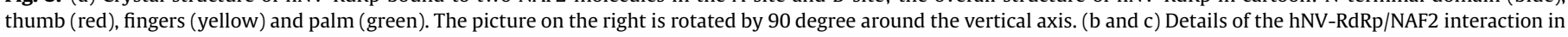

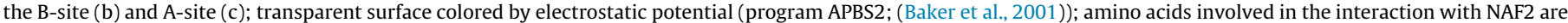

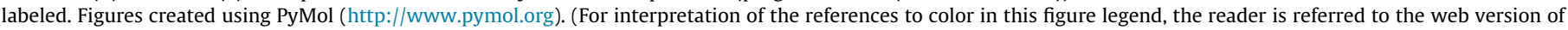
this article.) 
region close to the B-site described above. Therefore, for the present study, PPNDS was selected as a commercially available compound potentially useful to further characterize structural features of the newly identified B-site. Notably, we succeeded in obtaining crystals of hNV-RdRp bound to PPNDS only after soaking the protein with the inhibitor in the presence of dsRNA and GTP (see Section 2.5 for details). This suggests that inhibitor binding to the protein requires local structural changes related to events in the catalytic cycle. The protein crystal structure was refined to a final crystallographic $R$-factor of $22.0 \%$, and $R$-free of $28.5 \%$, for the $2.6 \AA$ resolution data set (Table 2 ). As predicted by the docking study, PPNDS binds only to the B-site (Fig. 4, Fig. S3a and b). The overall structure of the whole enzyme bound to PPNDS appears slightly more compact relative to that of the inhibitor-free protein (pdb-id 1SH0; r.m.s.d. $1.01 \AA$ A, over $484 \mathrm{C} \alpha$ pairs (Ng et al., 2004)). Such overall effect is related to a small displacement of both the fingers and the thumb domains toward the active site, as in a closing hand, and is likely due to the interaction of the protein with dsRNA (Fig. 4a and b). In fact, the crystal structure shows residual electron density hosted between the fingers and thumb domains compatible with two or three RNA nucleotides, which have been only partially modeled in the refined structure, due to electron density ambiguities. The nucleotides are hosted in a positively charged region along the exit pathway of the newly formed RNA chain (Zamyatkin et al., 2008).

The PPNDS molecule can be schematically divided into two moieties, the naphthalene $6^{\prime}$-nitro- $4^{\prime}, 8^{\prime}$-disulfonate and the pyridoxal-5'-phosphate, linked by the azo bond (Fig. 1b). The nitro group of the first moiety is tightly hosted in a hydrophobic cleft, between helices $\alpha 13$ and $\alpha 14$ of the thumb domain, lined with Leu406, Ile411 ( $\alpha 13$ ), Leu443 ( $\alpha 14)$, Val504 (C-terminal) and with the aliphatic portion of the side chains of Ser 410 ( $\alpha 13), \ln 414$ $(\alpha 13)$ and Glu446 ( $\alpha 14)$ (Fig. 4c, Fig. S3b). Both PPNDS sulfonate groups point toward the solvent; the $8^{\prime}$ sulfonate establishes hydrogen bonds with $\operatorname{Gln} 414$ and $G \ln 439$, while the 4' sulfonate is H-bonded to Ser410 and salt bridges with Arg413 and Arg392 (Fig. 4c). The naphthalene ring is in van der Waals contacts with Gln414. The PPNDS pyridoxal-5'-phosphate group is elongated toward the fingers domain, stabilizing the conformation of the Cter end of hNV-RdRp within the active site cavity (Fig. 4a and c). In fact, while in the inhibitor-free enzyme the C-ter is modeled in the electron density up to Glu506-Asp507, when PPNDS is present all the C-ter residues can be modeled (Glu510 is in van der Waals contact with the pyridoxal moiety, and H-bonded to its phosphate group). Interestingly, the PPNDS phosphate group points toward the active site region in the palm domain, which is rich in negatively charged amino acids, partially masked by $\operatorname{Arg} 182, \operatorname{Arg} 392$ and $\mathrm{Mg}^{2+}$. Finally, the carbonyl group of the pyridoxal ring is H-bonded to Glu168. Relative to NAF2, the PPNDS molecule appears to be shifted toward the palm domain of about two $\alpha$ helical turns $(\sim 6-7 \AA)$ along the direction of the antiparallel helices $\alpha 13$ and $\alpha 14$. Such PPNDS location may be dictated by the nitro group that cannot be properly hosted in the NAF2 cavity due to clash with Trp417 main chain (in the $\alpha 13-\beta$ motif of the thumb domain). Notably, the location of PPNDS at a site different from the previously identified A-site is independently assessed by the close matching of the $\mathrm{IC}_{50}$ values obtained (as described above) for w.t. hNV-RdRp (Table 1) and for its Y41A mutant, where a key residue building the A-site is replaced by Ala (IC $C_{50}$ of about $500 \pm 50 \mathrm{nM}$ ). In fact, such a mutation was previously shown to affect suramin and NF023 inhibitory effects on hNV-RdRp (Mastrangelo et al., 2012).

\section{Discussion}

In a previous work (Mastrangelo et al., 2012) we showed that suramin and NF023 binding site to mNV-RdRp, and to hNV-RdRp, as inferred by crystal structures and mutation analysis, is located along the access pathway of NTPs to the enzyme active center. Accordingly, such site is lined with positively charged residues whose conformational flexibility helps promoting the diffusion of NTPs toward the catalytic site. Such structural features are unlikely to make this inhibitor binding site an ideal target region for structure based drug optimization. We therefore decided to analyze the structural and inhibitory properties of fragments of the

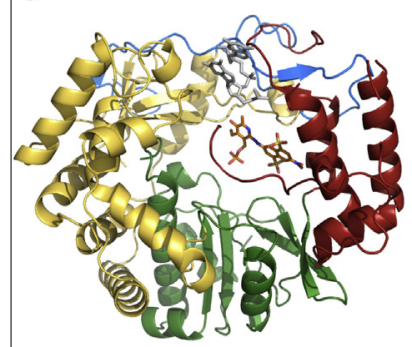

b

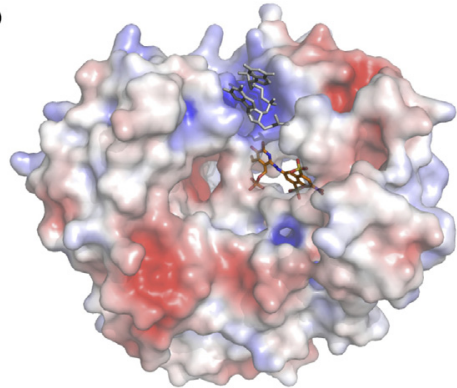

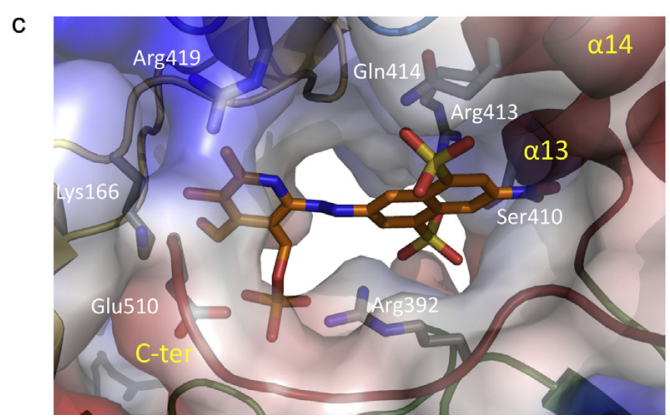

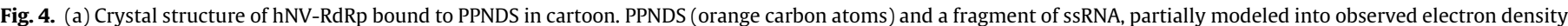

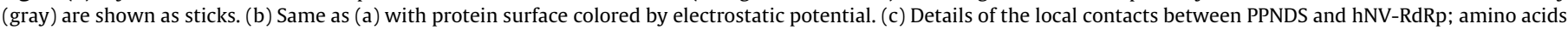

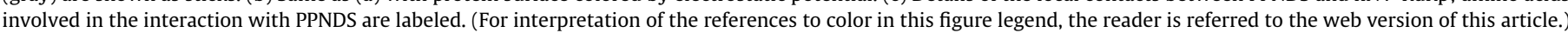


identified inhibitors, focusing on their naphthalene-sulfonate moieties, thus selecting the NAF2 compound. Enzymatic assays showed that the selected fragment of the initial inhibitors still retains marginal inhibitory activity. More importantly, besides the site previously characterized in the suramin/NF023 complexes (here identified as the A-site), such reverse fragment screening experiments unraveled a novel, unexpected, binding site for NAF2, located in the RdRp thumb domain (B-site). Interestingly, the B-site is located in a position that is roughly structurally equivalent to the benzothiadiazine inhibitor binding site in the Hepatitis C Virus RdRp (Koch and Narjes, 2006; Pfefferkorn et al., 2005). NAF2 binding to two distinct sites is also suggested by analysis of the inhibition mechanism which shows a Hill coefficient higher than 1. In order to further characterize the B-site we selected PPNDS, a naphthalene sulfonate-based compound that is a potent and selective P2X1 receptor antagonist (Lambrecht et al., 2000). We demonstrated that PPNDS is able to inhibit the polymerase activity (Hill coefficient $\sim 1$, Fig. S1b) with a potency close to that observed for suramin or NF023. The crystal structure of the hNVRdRp/PPNDS complex shows that the compound is anchored to the protein mostly through its naphthalene moiety. On the other hand, the improved inhibitory efficacy is likely dependent on PPNDS pyridoxal moiety that extends toward the enzyme active site. Such consideration is in keeping with the fact that: (i) NAF2 does not exert considerable inhibition, and (ii) PPNDS helps fixing the C-terminal end of the enzyme inside the active site, likely blocking the access of both the ssRNA template and the NTPs. The discovery of a new inhibitor binding site, and our analysis of the PPNDS binding mode to hNV-RdRp, provide new structural bases for modification of PPNDS and/or related compounds, in order to improve its efficacy and drug-likeness.

\section{Acknowledgment}

This work was funded by the FP7 HEALTH-2010 Collaborative Project SILVER (No. 260644).

\section{Appendix A. Supplementary data}

Supplementary data associated with this article can be found, in the online version, at http://dx.doi.org/10.1016/j.antiviral. 2013.11.016.

\section{References}

Baker, N.A., Sept, D., Joseph, S., Holst, M.J., McCammon, J.A., 2001. Electrostatics of nanosystems: application to microtubules and the ribosome. Proc. Natl. Acad. Sci. USA 98, 10037-10041.

Beindl, W., Mitterauer, T., Hohenegger, M., Ijzerman, A.P., Nanoff, C., Freissmuth, M., 1996. Inhibition of receptor/G protein coupling by suramin analogues. Mol. Pharmacol. 50, 415-423.

Berman, H.M., Westbrook, J., Feng, Z., Gilliland, G., Bhat, T.N., Weissig, H., Shindyalov, I.N., Bourne, P.E., 2000. The protein data bank. Nucleic Acids Res. 28, 235-242.
Bok, K., Green, K.Y., 2012. Norovirus gastroenteritis in immunocompromised patients. N. Engl. J. Med. 367, 2126-2132.

Charlton, S.J., Brown, C.A., Weisman, G.A., Turner, J.T., Erb, L., Boarder, M.R., 1996. PPADS and suramin as antagonists at cloned P2Y- and P2U-purinoceptors. Br. J. Pharmacol. 118, 704-710.

Clarke, I.N., Lambden, P.R., 2000. Organization and expression of calicivirus genes. J. Infect. Dis. 181 (Suppl. 2), S309-316.

Emsley, P., Lohkamp, B., Scott, W.G., Cowtan, K., 2010. Features and development of Coot. Acta Crystallogr. Sect. D 66, 486-501.

Evans, P., 2006. Scaling and assessment of data quality. Acta Crystallogr. D: Biol. Crystallogr. 62, 72-82.

Fauquet, C.M., Fargette, D., 2005. International committee on taxonomy of viruses and the 3,142 unassigned species. Virol. J. 2, 64.

Fullerton, S.W., Blaschke, M., Coutard, B., Gebhardt, J., Gorbalenya, A., Canard, B., Tucker, P.A., Rohayem, J., 2007. Structural and functional characterization of sapovirus RNA-dependent RNA polymerase. J. Virol. 81, 1858-1871.

Green, K.Y., 2007. Caliciviridae: the noroviruses. In: Knipe, D.M., Howley, P.M. (Eds.), fifth 144 ed. Fields Virology, vol. 1. Lippincott Williams \& Wilkins, a 145 Wolters Kluwer Business, Philadelphia, USA, pp. 41-51.

Green, K.Y., Ando, T., Balayan, M.S., Berke, T., Clarke, I.N., Estes, M.K., Matson, D.O. Nakata, S., Neill, J.D., Studdert, M.J., Thiel, H.J., 2000. Taxonomy of the caliciviruses. J. Infect. Dis. 181 (Suppl. 2), S322-330.

Kabsch, W., 2010. Xds. Acta Crystallogr. D: Biol. Crystallogr. 66, 125-132.

Klinger, M., Bofill-Cardona, E., Mayer, B., Nanoff, C., Freissmuth, M., Hohenegger, M., 2001. Suramin and the suramin analogue NF307 discriminate among calmodulin-binding sites. Biochem. J. 355, 827-833.

Koch, U., Narjes, F., 2006. Allosteric inhibition of the hepatitis C virus NS5B RNA dependent RNA polymerase. Infect. Disord. Drug Targets 6, 31-41.

Lambrecht, G., Rettinger, J., Baumert, H.G., Czeche, S., Damer, S., Ganso, M., Hildebrandt, C., Niebel, B., Spatz-Kumbel, G., Schmalzing, G., Mutschler, E., 2000. The novel pyridoxal-5'-phosphate derivative PPNDS potently antagonizes activation of P2X(1) receptors. Eur. J. Pharmacol. 387, R19-21.

Mastrangelo, E., Pezzullo, M., Tarantino, D., Petazzi, R., Germani, F., Kramer, D. Robel, I., Rohayem, J., Bolognesi, M., Milani, M., 2012. Structure-based inhibition of Norovirus RNA-dependent RNA polymerases. J. Mol. Biol. 419, 198-210.

Mayo, M.A., 2002. A summary of taxonomic changes recently approved by ICTV. Arch. Virol. 147, 1655-1663.

Ng, K.K., Pendas-Franco, N., Rojo, J., Boga, J.A., Machin, A., Alonso, J.M., Parra, F., 2004. Crystal structure of norwalk virus polymerase reveals the carboxyl terminus in the active site cleft. J. Biol. Chem. 279, 16638-16645.

Patel, M.M., Widdowson, M.A., Glass, R.I., Akazawa, K., Vinje, J., Parashar, U.D., 2008 Systematic literature review of role of noroviruses in sporadic gastroenteritis. Emerg. Infect. Dis. 14, 1224-1231.

Pfefferkorn, J.A., Greene, M.L., Nugent, R.A., Gross, R.J., Mitchell, M.A., Finzel, B.C. Harris, M.S., Wells, P.A., Shelly, J.A., Anstadt, R.A., Kilkuskie, R.E., Kopta, L.A., Schwende, F.J., 2005. Inhibitors of HCV NS5B polymerase. Part 1: Evaluation of the southern region of (2Z)-2-(benzoylamino)-3-(5-phenyl-2-furyl)acrylic acid. Bioorg. Med. Chem. Lett. 15, 2481-2486.

Prinz, H., 2010. Hill coefficients, dose-response curves and allosteric mechanisms. J. Chem. Biol. 3, 37-44.

Read, R., Sussman, J., Leslie, A.W., Powell, H., 2007. Processing Diffraction Data with Mosflm, Evolving Methods for Macromolecular Crystallography. Springer, Netherlands, pp. 41-51.

Rohayem, J., Bergmann, M., Gebhardt, J., Gould, E., Tucker, P., Mattevi, A., Unge, T. Hilgenfeld, R., Neyts, J., 2010. Antiviral strategies to control calicivirus infections. Antiviral Res. 87, 162-178.

Smart, O.S., Womack, T.O., Flensburg, C., Keller, P., Paciorek, W., Sharff, A., Vonrhein, C., Bricogne, G., 2012. Exploiting structure similarity in refinement: automated NCS and target-structure restraints in BUSTER. Acta Crystallogr. Sect. D 68, 368 380.

Steiner, R.A., Lebedev, A.A., Murshudov, G.N., 2003. Fisher's information in maximum-likelihood macromolecular crystallographic refinement. Acta Crystallogr. Sect. D 59, 2114-2124.

Vagin, A., Teplyakov, A., 1997. MOLREP: an automated program for molecular replacement. J. Appl. Crystallogr. 30, 1022-1025.

Zamyatkin, D.F., Parra, F., Alonso, J.M., Harki, D.A., Peterson, B.R., Grochulski, P., Ng, K.K., 2008. Structural insights into mechanisms of catalysis and inhibition in Norwalk virus polymerase. J. Biol. Chem. 283, 7705-7712. 